MARINE MAMMAL SCIENCE, 11(1):100-106 (January 1995)

(C) 1995 by the Society for Marine Mammalogy

\title{
RESPONSES TO CALF ENTANGLEMENT IN FREE-RANGING BOTTLENOSE DOLPHINS
}

Entanglement in fishing gear poses severe risks to dolphins and is of enormous ecological concern (Brownell et al. 1989, Perrin et al., in press). Monofilament line does not degrade quickly in water and can cause severe injury or death to numerous forms of marine life. Little is known about the responses of dolphin mothers to injured or entangled calves. Here, we describe the behavior of a freeranging dolphin mother and infant before and after the infant became entangled in fishing line.

Our study population of bottlenose dolphins (Tursiops sp.) ranges in the 


\section{Help Volumes Main Menu}

coastal waters of Shark Bay, Western Australia. Shark Bay offers unique opportunities for study of wild dolphin behavior and ecology. At Monkey Mia, a small fishing camp in Shark Bay, several dolphins routinely enter shallow water and accept hand-fed fish from tourists (Connor and Smolker 1985). These dolphins are part of a larger population in the area. Over 400 are recognized, and approximately 100 individuals are regularly followed using focal-animal sampling methods (Altmann 1974). The entanglement reported here occurred during a focal follow on a mother and infant pair.

We follow dolphins in 3.5-m aluminum dinghies powered by two 6-hp Evintude outboard engines. The dolphins are well habituated to our presence and allow us to follow at very close ranges (typically $5-20 \mathrm{~m}$ ). During focal follows we use a combination of continuous, scan, point, ad libitum, and predominant activity sampling to mcasure spatial relationships, focal and party activity, party composition (using a $10-\mathrm{m}$ chain rule, i.e., any animal within 10 $m$ of a party member is considered to be a member of the party, see Smolker et al. 1992), speed, distance travelled, diving and surfacing patterns, and other information.

One mother-infant pair, SQU and PEG, is the focus of this paper. PEG, a female infant, was born between October and December in 1989. Her mother, SQU, has at least one older surviving daughter. They are not provisioned and do not have human contact.

On April 29, 1990 we conducted a focal follow on SQU and PEG from 1150 to 1720 ( $5.5 \mathrm{~h}$ in total). Their behavior and associations throughout the follow are summarized in Table 1 . In sum, SQU and PEG predominantly rested and travelled slowly $(<3 \mathrm{~km} / \mathrm{h})$ from 1150 to 1545 . At 1557 , during a play bout with another infant, PEG became entangled in monofilament line. From 1557 until we lost them at 1720 , mother and infant leaped and travelled rapidly $(>6.5 \mathrm{~km} / \mathrm{h})$, changing direction frequently. Two different parties of dolphins joined PEG and SQU at different times and leaped synchronously with them for about $10 \mathrm{~min}$. The following day we found SQU and PEG by themselves at 1000. PEG was no longer entangled and although she had some small lacerations (which developed into permanent scarring on the anterior edge of her dorsal fin), she appeared to be fine. Both mother and infant were behaving as they did before the incident.

We will now discuss four major changes in the behavior of SQU and PEG prior to and following the entanglement event: mother-infant proximity, activity, synchrony, and travel speed (see Table 2). Mother-infant proximity and activity were measured using scan samples every $2.5 \mathrm{~min}$. Travel speed was estimated using the predominant boat speed over each 5-min interval. All occurrences of synchronous surfacings were recorded. Scan sample and actual frequencics wcre used to compare before entanglement and after entanglement data.

Point-sample proximity measures between mother and infant were delineated into several categories including: infant position (infant slightly behind and underneath the mother), $\leq 30 \mathrm{~cm}$ but not in infant position, $>30 \mathrm{~cm}$ but $\leq 2$ $\mathrm{m},>2 \mathrm{~m}$ but $\leq 5 \mathrm{~m}$. Larger distances were not observed during this follow. As illustrated in Table 2, after entanglement PEG spent less time in infant 


\section{Help Volumes Main Menu}

Table 1. Summary of events on April 29, 1990.

\begin{tabular}{|c|c|c|c|}
\hline Time & Events & Activity & Notes \\
\hline $11: 50$ & $\begin{array}{l}\text { Focal on PEG \& SQU begins; group composition is } \\
\text { PEG SQU YOG SMO }\end{array}$ & slow travel, rest & SMO is $1.5 \mathrm{yr}$ old infant of YOG \\
\hline $12: 43$ & Group joined by COS PII JFR & slow travel, rest & PII is $2-3$ mo-old infant of COS \\
\hline $12: 17$ & COS PII leave group & slow travel, rest & \\
\hline $13: 06$ & JFR leaves group & slow travel, rest & \\
\hline $15: 45$ & Infants PEG and SMO play & socialize & \\
\hline $15: 57$ & $\begin{array}{l}\text { PEG dives, surfaces entangled in fishing line. PEG } \\
\text { YOG SMO leap, PEG briefly in infant position } \\
\text { with SQU; SMO in infant position }\end{array}$ & & $\begin{array}{l}\text { Whistles heard through the hydrophone. Line } \\
\text { seen around PEG's head and dorsal fin. } \\
\text { Hook possibly lodged in dorsal fin, ball of } \\
\text { tangled line trailing } 1-2 \mathrm{~m} \text { behind her }\end{array}$ \\
\hline $15: 58$ & SQU PEG leave area & fast travel, leaping & \\
\hline $16: 41$ & $\begin{array}{l}2-3 \text { animals join and leap synchronously with PEG } \\
\text { SQU for } 9 \text { min }\end{array}$ & fast travel, leaping & $\begin{array}{l}\text { SUR, an adolescent female, joined and stayed } \\
\text { for } \sim 30 \mathrm{~min}, \text { others stay } 9 \mathrm{~min}\end{array}$ \\
\hline $17: 02$ & $2-3$ animals join, leap synchronously & fast travel, leaping & Animals stay for $-10 \mathrm{~min}$ \\
\hline $17: 20$ & Lost PEG and SQU & fast travel, leaping & Visibility poor and rough seas \\
\hline
\end{tabular}




\section{Help Volumes Main Menu}

Table 2. Number of scans and proportion of time mother and infant spent in different activities and spatial states before and after infant became entangled in fishing line.

\begin{tabular}{|c|c|c|c|c|c|c|c|c|}
\hline \multirow{2}{*}{$\begin{array}{l}\text { Infant } \\
\text { activity }\end{array}$} & \multicolumn{2}{|c|}{ Rcst } & \multicolumn{2}{|c|}{ Infant position } & \multicolumn{2}{|c|}{ Social } & \multicolumn{2}{|c|}{ Fast travel } \\
\hline & \# Scans & $\%$ Time & \# Scans & $\%$ Time & \# Scans & \% Time & \# Scans & \% Time \\
\hline Before & 68 & 70.1 & 22 & 22.7 & 7 & 7.2 & 0 & 0 \\
\hline \multirow[t]{2}{*}{ After } & 0 & 0 & 0 & 0 & 0 & 0 & 30 & 100 \\
\hline & \multicolumn{2}{|c|}{ Rest } & \multicolumn{2}{|c|}{ Forage } & \multicolumn{2}{|c|}{ Social } & \multicolumn{2}{|c|}{ Fast travel } \\
\hline Mother's activity & \# Scans & $\%$ Time & \# Scans & $\%$ Time & \# Scans & \% Time & \# Scans & $\%$ Time \\
\hline Before & 93 & 96.9 & 1 & 1.0 & 2 & 2.1 & 0 & 0 \\
\hline \multirow[t]{2}{*}{ After } & 0 & 0 & 0 & 0 & 0 & 0 & 30 & 100.0 \\
\hline & \multicolumn{2}{|c|}{ Infant position } & \multicolumn{2}{|c|}{$\leq 30 \mathrm{~cm}$} & \multicolumn{2}{|c|}{$>30 \mathrm{~cm}, \leq 2 \mathrm{~m}$} & \multicolumn{2}{|c|}{$>2 \mathrm{~m}, \leq 5 \mathrm{~m}$} \\
\hline Proximity & \# Scans & $\%$ Time & \# Scans & $\%$ Time & \# Scans & $\%$ Time & \# Scans & $\%$ Time \\
\hline Before & 28 & 28.3 & 33 & 33.3 & 37 & 37.4 & 1 & 1.0 \\
\hline \multirow[t]{2}{*}{ After } & 0 & 0 & 31 & 93.9 & 0 & 0 & 2 & 6.1 \\
\hline & \multicolumn{2}{|c|}{ Slow } & \multicolumn{2}{|c|}{ Fast } & & & & \\
\hline Travel speed & \# Scans & $\%$ Time & \# Scans & $\%$ Time & & & & \\
\hline Before & 51 & 100 & 0 & 0 & & & & \\
\hline After & 0 & 0 & 16 & 100 & & & & \\
\hline
\end{tabular}




\section{Help Volumes Main Menu}

position, but more time close to her mother $(\leq 30 \mathrm{~cm})$, and less time at larger distances from her mother $(>30 \mathrm{~cm})$.

Infant and maternal activities changed dramatically from before to after the entanglement. Predominant activity measures, sampled at 2.5 -min intervals, show that before the entanglement both mother and infant spent most of their time resting and travelling slowly. The infant also engaged in some play, and the mother foraged briefly. After entanglement fast travel was the exclusive activity of both mother and infant (sce Table 2).

Synchronous breaths or synchrony are defined as conditions where two or more animals simultaneously break the water surface and/or submerge again simultaneously, in exact synchrony. Typically, mother and infant are parallel when surfacing synchronously, but synchronous surfacings in infant position, when the infant is slightly behind the mother, are also observed. The number of synchronous surfacings per minute changed from 0.20 before entanglement, to 3.37 after entanglement. Mean time intervals between synchronous surfacings were $4 \mathrm{~min} 28 \mathrm{sec}(S D=4 \mathrm{~min} 13 \mathrm{sec}$ ) before entanglement, and only $15 \mathrm{sec}$ $(\mathrm{SD}=19 \mathrm{sec})$ after entanglement. Before entanglement most of the dyad's breaths were not synchronous, whereas after entanglement nearly every breath was synchronous. When two distinct parties joined PEG and SQU following entanglement, they too, leaped synchronously with the pair and remained in close proximity. Although not all quadruple and quintuple synchronous leaps (synchronous leaps involving four or more animals) were counted, at least 3050 occurred. Quadruple and quintuple synchronous surfacings are rare. Out of $656 \mathrm{~h}$ of focal data collected between 1989 and 1992 on 22 mother-infant pairs, only nine quadruple and one quintuple synchronous surfacings have been observed.

Boat speed was categorized at 5 -min intervals as slow $(\leq 3 \mathrm{~km} / \mathrm{h})$, moderate $(4-6 \mathrm{~km} / \mathrm{h})$ and fast $(>6 \mathrm{~km} / \mathrm{h})$. PEG and SQU increased their speed from slow travel before entanglement, to fast travel following entanglement (Table 2). No moderate speeds occurred during the focal follow. Similarly, the frequency of leaping increased from 0 times per minute before entanglement to 5.5 times per minute after entanglement.

Reactions to stressful events are difficult to interpret. SQU's and PEG's rapid travel and continuous leaping may have been an attempt to dislodge the fishing line. Although getting caught in fishing line per se is an evolutionary novelty, and one would not expect dolphin mothers and calves to necessarily behave "adaptively" in such contexts, getting caught in seaweed, or being latched onto by a Remora may not be unusual, and high leaps and fast travel may be an adaptive response to such situations.

It is also possible that PEG and SQU perceived the trailing ball of fishing line as chasing them and thus increased their speed and changed direction frequently in response to "being pursued." This interpretation does not explain why other animals should suddenly join and leap synchronously with them. PEG's high leaps immediately following entanglement suggest that she perceived something as attached to her, rather than pursuing her, because these initial leaps landed her in roughly the same spot. 


\section{Help Volumes Main Menu}

Although we cannot generalize from one instance alone, behavioral changes in response to this event were dramatic and consistent. The fact that mother and infant remained extremely close and synchronous throughout the event exemplifies the strength of the mother-infant bond. It is unclear why other animals joined with the pair. Could the proximity and synchrony of the mother and animals who joined briefly be "sympathetic" responses to the infant, or simply efforts to remain with the injured animal for another reason? Synchronous behavior may be necessary during fast travel if dolphins want to stay together, but this suggests that others were at least interested in or attracted to the event. The other animals may have suspected that PEG and SQU were leap-feeding (type of foraging associated with large schools of fish), joined to share in the resources, and left upon realizing that this was not the case.

Although PEG eventually became freed from the fishing line, she was not immediately successful. Infants may be particularly vulnerable to entanglement because of their inexperience, playfulncss, curiousity, and small size. In previous incidents three of the semiprovisioned Shark Bay dolphin infants were entangled, but because they were accustomed to human contact, they were easily captured and the line was removed. Systematic data on these events are not available, but local observers noted leaping by the calves in all three cases. PEG's experience underscores the need for strict regulations against discarding fishing line in the water and better protection of marine habitats in general.

\section{ACKNOWLEDGMENTS}

We thank Julie Gros-Louis for assistance with data collection. Bernd Würsig and Elizabeth Gawain helped to initiate research at Monkey Mia. Stephen Dawson, James Rieger, Richard Connor, Andrew Richards, and one anonymous reviewer provided helpful comments on the manuscript. The project was supported by a National Science Foundation Presidential Young Investigator Award to BBS (BNS-8857969); private donations to the Dolphins of Shark Bay Research Foundation, and Woodrow Wilson and American Association of University Women fellowships to JM. Logistical support from the West Australian Museum, The University of Western Australia, The Department of Conservation and Land Management in West Australia, the Shire of Shark Bay, and the rangers at Monkey Mia are gratefully acknowledged.

\section{Literature Cited}

Altmann, J. 1974. Observational study of behaviour: sampling methods. Behaviour 49:227-267.

Brownell, R. L., JR., K. Ralls and W. F. Perrin. 1989. The plight of the 'forgotten' whales: it's mainly the small cetaceans that are now in peril. Oceanus 32:5-11.

CONNOR, R. C., AND R. A. Smolker. 1985. Habituated dolphins (Tursiops sp.) in Western Australia. Journal of Mammalogy 66:398-400.

Perrin, W. F., G. Donovan and J. Barlow, eds. In press. Gillnets and cetaceans: proceedings of the conference on mortality of cetaceans in passive fishing nets and traps. Reports of the International Whaling Commission, Special Issue.

Smolker, R. A., A. F. Richards, R. C. Connor and J. W. Pepper. 1992. Sex differenccs in patterns of association among Indian ocean bottlenose dolphins. Behaviour 123: $38-69$. 
Janet Mann, Department of Psychology, Georgetown University, Washington, D.C. 20057; Rachel A. Smolker and Barbara B. Smuts, Department of Psychology, 580 Union Drive, The University of Michigan, Ann Arbor, Michigan 48109-1346. Received 10 June 1993. Accepted 11 July 1994. 